\title{
INSTITUTIONAL EFFICIENCY OF SELECTED EU \& OECD COUNTRIES USING DEA-LIKE APPROACH
}

\author{
Jana Votápková, Milan Žák*
}

\begin{abstract}
The paper estimates institutional efficiency of a sample of EU and OECD countries. We employ an output-oriented Data Envelopment Analysis (DEA-like) approach where six Worldwide Governance Indicators published by the World Bank in 2009 constitute a vector of outputs. Assuming that all countries should aim at the same level of institutional quality, inputs were considered unimportant. The results, as to in which areas and how much individual countries need to improve, were not surprising. Concerning the overall efficiency scores and rankings, the most institutionally efficient countries are situated in northern Europe. The Czech Republic ranked $24^{\text {th }}$ in the overall sample and $3^{\text {rd }}$ among New EU Member States. The biggest necessary improvements are in the area of government effectiveness and control of corruption. The robustness check using Principal Component Analysis revealed significant qualitative correlation with the DEA-like results, with the correlation coefficient of 0.9653 . We propose that both sets of results could be used equally well as explanatory variables in growth and other regressions.
\end{abstract}

Keywords: efficiency, institutions, Worldwide Governance Indicators, PCA.

JEL Classification: C61, E02

\section{Introduction}

There is little doubt that institutions matter in terms of economic performance and play an important role in economic development. If institutions are trustworthy, new businesses are created easily, larger scale and technologically demanding production takes place, trade flourishes, productivity increases, competitiveness improves and markets function efficiently in general. Institutions also contribute to the domestic and international division of labour. In other words, transaction costs in the entire economy are considerably reduced.

Positive effects of institutions on promoting economic growth and development, investment, prosperity and well-being of the society were first empirically confirmed

* Jana Votápková, Center for Economic Studies, University of Economics and Management (CES VŠEM), Prague, CZ; Institute of Economic Studies, Faculty of Social Sciences, Charles University, Prague, CZ (jana.votapkova@gmail.com); Milan Žák, Center for Economic Studies, University of Economics and Management (CES VŠEM), Prague, CZ (milan.zak@vsem.cz).

Financial support by the Research Grant of MŠMT (The Czech Ministry of Education) 1M0524 is gratefully acknowledged. 
by Kormendi, Meguire (1985) and Scully (1988). Later studies include Borrmann et al. (2006) or Chousa et al. (2004). A comprehensive survey of studies dealing with the effect of institutions on growth up to 2000 can be found in Aron (2000). Institutions were also found to exert a positive effect on the pattern of foreign direct investment (Gwartney et al., 2004), which suggests that bad institutions discourage foreign investment more than the domestic one. The link between institutions, poverty and unequal distribution of income has been empirically explored in Chong, Calderon (2000, 2000b), or Bourguignon, Verdier (2000). When explaining determinants of trade flows, Levchenko (2007) found that institutions also represent a source of comparative advantage causing factor prices to diverge in the countries which do not gain from trade. On the micro level, it was proved that corruption stifles entry of new firms, introduction of new products and technologies, increases uncertainty and worsens delivery of public services (Romer, 1994).

Appropriate measures of institutional quality have been a matter of a wide discussion. It has in some cases been proxied by measures of political stability (Barro, 1991), such as coups and revolutions and political assassinations Gastil (1983, 1986), measures of political freedoms and civil liberties (Kormendi, Meguire, 1985; Scully, 1988) or shadow economy and barter trade volumes (Chousa et al., 2004). Other studies employed institutional indicators by the International Country Risk Guide (ICRG) and Business Environmental Risk Intelligence (BERI) (Knack, Keefer, 1995; Chong, Calderon, 2000a; Mauro, 1995), Economic Freedom of the World indicators (Adkins et al., 2002; Gwartney et al., 2003, 2004), Freedom House's Democratization Index (Chousa et al., 2004), data from The Global Competitiveness Report (WEF, 1980-2010), the World Bank - Doing Business (World Bank, 2004-2011) or the Worldwide Governance Indicators previously called Government Matters (Borrmann et al., 2006).

In many cases more variables were aggregated to obtain an overall index which would encompass a larger area of institutional quality, for instance using Principal Component Analysis (PCA) (Adkins et al., 2002; Wheeler, Mody, 1992), composing an unweighted average (Chong, Calderon, 2000, 2000a, 2000b; Mauro, 1995; Knack, Keefer, 1995) or using the notion of efficiency (Chousa et al., 2004).

Our paper will contribute to this stream of research by analyzing the data from Kaufmann et al. (2010), i.e. the Worldwide Governance Indicators. Using a DEA-like output-oriented approach we will (1) obtain relative efficiency of selected OECD and EU countries in terms of quality of institutions which can serve as an institutional input to further analyses. We will then (2) answer in which of the six areas of institutional quality, the countries are relatively lacking and by how much. Our methodology was motivated by Chousa et al. (2004) who, even though not with DEA, also constructed a composite institutional variable using relative efficiency under the assumption that the institutional framework of leading developed countries is efficient. We will then (3) carry out a robustness check of the DEA results taking advantage of the Principal Component Analysis (PCA) and measure rank correlations of the results obtained from the respective methods. 
The paper is structured as follows. In Section 2 we will introduce the methodology of the Data Envelopment Analysis and its adjustment necessary for our purposes. Section 3 sheds light on the dataset. In Section 4 we will provide empirical results and discussion and Section 5 will conclude and provide motivation for further research.

\section{Methodology}

\subsection{Data Envelopment Analysis}

For the analysis of institutional quality we will use the Data Envelopment Analysis-like (DEA) method. It is a non-parametric deterministic ${ }^{1}$ frontier approach, the goal of which is to project an observation in the input-output space in its best possible light. First, the most efficient observations from the dataset form the efficiency frontier. Consequently, the distance of remaining observations from this frontier is determined and their relative level of inefficiency revealed.

For the purposes of this analysis we will employ a DEA output-oriented method, i.e. we will maximize a vector of six outputs given a $1 \times 1$ vector of inputs which will be set equal to 1 for all observations, assuming constant returns to scale.

For DEA cannot deal with potential outliers, which, if present, might cause serious ill to the results, ${ }^{2}$ we will also check statistical homogeneity of the sample (for further discussion see Section 3).

\subsubsection{Formulation}

Within the DEA framework, assume that a DMU produces $s$ different outputs, $\mathbf{y}=\left(y_{1}, \ldots, y_{s}\right)$ using $m$ different inputs $\mathbf{x}=\left(x_{1}, \ldots, x_{m}\right)$ and that there is a set of $\mathrm{n}$ DMUs, $\mathbf{N}=(1, \ldots, n)$. Consequently, the $i$-th DMU, $i \in \mathrm{N}$, is expressed in terms of its input and output vectors, such that $\mathrm{DMU}_{i}=\left(\mathbf{x}_{\mathrm{i}}, \mathbf{y}_{\mathrm{i}}\right)$

where $\mathbf{x}_{\mathrm{i}}=\left(\mathrm{x}_{1 \mathrm{i}}, \ldots, \mathrm{x}_{\mathrm{mi}}\right), \mathbf{y}_{\mathrm{i}}=\left(\mathrm{y}_{1 \mathrm{i}}, \ldots, \mathrm{y}_{\mathrm{si}}\right)$.

The relative efficiency of DMU can be obtained by solving the fractional program as proposed by Charnes et al. (1978, p. 430):

$$
\max _{\mathbf{u}_{\mathrm{i}}, \mathbf{v}_{\mathrm{i}}} \frac{\mathrm{u}_{\mathrm{i}}^{\prime} \mathbf{y}_{\mathrm{i}}}{\mathbf{v}_{\mathrm{i}}^{\prime} \mathbf{x}_{\mathrm{i}}}
$$

s.t.

1 The entire deviation is assumed to be caused by inefficiency, as opposed to stochastic approaches which acknowledge existence of random noise.

2 If there is an outlier among inefficient observations, it will under- or over-estimate results only for this particular observation, however, if the outlier appears among the most efficient observations forming the locus of the most efficient observations, it will shift the frontier and thus reveal wrong results for all other observations in the dataset. 


$$
\begin{gathered}
\frac{\mathbf{u}_{\mathrm{i}}^{\prime} \mathbf{y}_{\mathrm{j}}}{\mathbf{v}_{\mathrm{i}}^{\prime} \mathbf{x}_{\mathrm{j}}} \leq 1 \forall \mathrm{j} \in \mathrm{N} \\
\mathbf{u}_{\mathrm{i}}, \mathbf{v}_{\mathrm{i}} \geq 0
\end{gathered}
$$

where $\mathbf{u}_{\mathrm{i}}, \mathbf{v}_{\mathrm{i}}$ are vectors of weights attached to vectors of outputs $\mathbf{y}_{\mathrm{i}}$ and inputs $\mathbf{x}_{\mathrm{i}}$ respectively.

Put it differently, we aim to find a set of input and output weights $\left(\mathbf{u}_{\mathrm{i}}, \mathbf{v}_{\mathrm{i}}\right)$ which maximize efficiency of the under the constraint that if these maximizing weights are applied to each of the other DMUs in the dataset, they lie on, or under the locus of fully efficient observations. It results that the linear program must be run times, once for each DMU.

In our case, the fractional problem will immediately reduce to a multiplier form (Charnes et al., 1978) since our input vector consists of just one element equal to 1 for all DMUs. Finding optimal input weights thus looses justification. The denominator of (1) will then be:

$$
\mathbf{v}_{\mathrm{i}}^{\prime} \mathbf{x}_{\mathrm{i}}=1
$$

Since maximization and minimization are dual problems, we will take advantage of Shephard's (1970) output distance function, where subscript stand for ,output“, which is reciprocal to Farrell's (1957) measure of output oriented technical efficiency, such that:

$$
\mathrm{D}_{0}\left(\mathrm{x}_{\mathrm{i}}, \mathbf{y}_{\mathbf{i}}\right)=\min \left\{\lambda_{\mathrm{i}}:\left(\frac{\mathbf{y}_{\mathbf{i}}}{\boldsymbol{\lambda}_{\mathrm{i}}}\right) \in \mathrm{P}(\mathrm{x})\right\}
$$

for $\boldsymbol{y}_{i} \in P(x)$, where $\mathrm{P}(\mathrm{x})=\left\{\mathbf{y}_{\mathrm{i}}:\left(\mathrm{x}_{\mathrm{i}}, \mathbf{y}_{\mathrm{i}}\right) \in \mathrm{T}\right\}$, which represents output set of the production technology and $\mathrm{D}_{0}\left(\mathrm{x}_{\mathrm{i}}, \mathbf{y}_{\mathbf{i}}\right) \leq 1$. Further $\mathbf{y}_{\mathbf{i}}: \in \mathrm{I}(\mathrm{x})$, where $\mathrm{I}(\mathrm{x})=\left\{\mathrm{x}_{\mathrm{i}}: \mathrm{x}_{\mathrm{i}} \in \mathrm{L}(\mathrm{y}), \lambda_{\mathrm{i}} \mathrm{x}_{\mathrm{i}} \notin \mathrm{L}(\mathrm{y}), \lambda<1\right\}$ is the input isoquant with $\mathrm{L}(\mathrm{y})=$ $\left\{\mathrm{x}_{\mathrm{i}}:\left(\mathbf{y}_{\mathrm{i}}, \mathrm{x}_{\mathrm{i}}\right) \in \mathrm{T}\right\}$ representing the input set of the technology and $\mathrm{D}_{0}\left(\mathrm{x}_{\mathrm{i}}, \mathbf{y}_{\mathbf{i}}\right)=1$. The input $\mathrm{I}(\mathrm{x})$ isoquant thus represents the locus of fully efficient observations in the input space. Given standard assumptions on the production set $\mathrm{T}=\left\{\left(\mathbf{y}_{\mathrm{i}}, \mathrm{x}_{\mathrm{i}}\right): \mathrm{x}_{\mathrm{i}}\right.$ can produce $\left.\mathbf{y}_{\mathrm{i}}\right\}$, the output distance function $\mathrm{D}_{0}\left(\mathrm{x}_{\mathrm{i}}, \mathbf{y}_{\mathbf{i}}\right)$ is non-increasing in $x$ and is non-decreasing, homogeneous of degree +1 and convex in $\boldsymbol{y}$. Subscript $i$ again denotes the $\mathrm{DMU}_{i}$ under scrutiny.

We thus minimize $\lambda_{i}$, i.e. a vector of weights attached to $\mathrm{DMU}_{i}$ to cast it in the best possible light. In other words, if we divide the vector of outputs of $\mathrm{DMU}_{i}$ by the optimal $\lambda$ vector, i.e. increase it by the particular proportion, the DMU concerned would be projected as feasible and efficient. That is, we have determined its distance to the frontier.

Similar to the fractional and multiplier forms, running $n$ problems is needed. The vector $\boldsymbol{\lambda}$ is thus specific for each DMU. However, the advantage of the distance function stems from the fact that it involves fewer constraints than factional or multiplier representations. 
We will consider only constant returns to scale assumption, since all the countries should be able to achieve the best possible scores regarding the institutional quality variables. The size of the country is assumed not to play a role.

\subsection{Robustness check}

As a robustness check of the efficiency results obtained from DEA, we will carry out a Principal Component Analysis (PCA) which will allow us to aggregates all the institutional variables into one indicator. It is based on common components of the data. Variances in the data are projected as a new coordinate system. The greatest variance lies on the first coordinate, the second biggest variance constitutes the second coordinate, which is, however, uncorrelated with the first one, etc. Only the greatest variances are taken into account and a lower dimensional data is constructed (for more explanation see e.g. Jolliffe, 2002.) Considering only the biggest variance, we will construct our matrix into a vector.

Since PCA only rescales the matrix as opposed to DEA, correlation of the two sets of results is irrelevant. We are instead interested in the Spearman's Rank Correlation Coefficient (Spearman, 1904):

$$
\begin{gathered}
\rho=1-\frac{6 \times \sum d^{2}}{n\left(n^{2}-1\right)} \\
\rho \in\langle-1,1\rangle
\end{gathered}
$$

where $d$ stands for the difference in the ranks and $n$ is the number of pairs compared. The highest rank is assigned to the most efficient observation (under DEA) and the highest indicator value (under PCA). When there are more observations with the same score, however, (e.g. fully efficient countries under DEA), their resulting rank is an average of the ranks which otherwise would be the case. There are unlikely to be two identical results under PCA since they are obtained as matrix multiplication. This might therefore result in a slight downward bias in the rank correlation coefficient for the two methods, which has to be kept in mind when interpreting the results.

\section{Data}

The data on institutional variables was obtained from the Database of Worldwide Governance Indicators (Kaufmann et al., 2010). ${ }^{3}$ Even though this data is perceptionbased, we believe that our dataset is considerably robust since each of the six indicators is based on a several hundred variables obtained from 31 different data sources (Kaufmann et al., 2010). Being provided with standard errors of each indicator, we excluded insignificant variables and thus reduced much of error or possible bias in the

3 Available online under http://info.worldbank.org/governance/wgi/sc country.asp 
data. Significance of variables was tested using the standard Student's T-test with 90, 95 and 99 percent confidence intervals.

The final dataset for our analysis consists of a cross-section of 35 countries observed in 2009, all of which are EU-27 and OECD members, or both. However, we initially considered 48 countries, which covered all 34 OECD countries + Russia as an EU candidate, EU-27 countries which are not OECD members, EU candidates, i.e. Croatia, Monte Negro, Macedonia (former Yugoslavia), and EU potential candidates, i.e. Albania, Bosnia and Herzegovina, Serbia and Kosovo. The rationale to include all these countries was consistent with Chousa et al. (2004) who argued that institutional quality becomes particularly important when advanced forms of global, regional or economic integration are at stake. Unfortunately, after initial check of the data we excluded 18 countries due to data inconsistency. Specifically, a country was excluded if more than 2 out of 6 variables were insignificant, or if besides two significant variables, others were significant at only 95 or $90 \%$. Besides, we also excluded Russia and Israel, the values of which were significant but extremely low with respect to the rest of the sample. These two countries were utmost likely to be outliers, to which the DEA methodology is very sensitive. The input data for Italy and Greece also suggest that we should be cautious when interpreting their results. Specifically, 2 variables were insignificant in case of Greece, the remaining variables were significant even at $1 \%$ level. Italy reported only one insignificant variable, however, three others were significant at $95 \%$ confidence interval only. The final list of countries is included in the appendix in Tables A2 and A3.

\subsection{Output and Input Variables}

Six variables of institutional quality that aim to define "traditions and institutions by which authority in a country is exercised" (Kaufmann et al., 2010, p. 4) enter the analysis as a vector of outputs. They address different spheres of the overall government performance. The indicators can be divided into three areas, which include (Kaufmann et al., 2010):

I. Process by which governments are selected, monitored and replaced

(1) Voice and Accountability

(2) Political Stability and Absence of Violence/Terrorism

II. Capacity of the government to effectively formulate and implement sound policies

(3) Government Effectiveness

(4) Regulatory Quality

III. Respect of citizens and the state for the institutions that govern economic and social interactions among them

(5) Rule of Law

(6) Control of Corruption 
Specifically, voice and accountability capture the perception of the extent to which citizens can participate in electing government, can exercise freedom of expression, freedom of association and free media. Political stability and absence of violence/ terrorism captures the perception of the probability that the government will be destabilized or overthrown by unconstitutional or violent means, including politicallymotivated violence and terrorism. Government effectiveness measures the perception of the quality of public services, civil service and the degree of its political independence, the quality of policy formulation and implementation and the credibility of the government's commitment to such policies. Regulatory quality then represents perception of the extent to which governments can formulate and implement sound policies and regulations that permit and promote private sector development. Rule of law belongs to the last group of indicators and captures the confidence the agents have in rules, particularly the quality of contract enforcement, property rights, police and courts and their perception of the likelihood of crime and violence. The last indicator, control of corruption, captures the perception of the extent to which public power is exercised for private gains, including all forms of corruption (Kaufmann et al., 2010, p. 4). All the six estimated variables in the database span from approximately -2.5 to +2.5 , however, countries included in this analysis consistently reveal only data above zero in all areas. Descriptive statistics of the data is reported in Table 1.

Table 1

Descriptive Statistics

\begin{tabular}{|l|c|c|c|c|c|}
\hline Variable & Mean & Median & Minimum & Maximum & St. dev. \\
\hline voice and accountability & 1.225 & 1.210 & 0.690 & 1.570 & 0.259 \\
\hline political stability & 0.896 & 0.915 & 0.410 & 1.440 & 0.263 \\
\hline government effectiveness & 1.339 & 1.320 & 0.520 & 2.190 & 0.455 \\
\hline regulatory quality & 1.318 & 1.350 & 0.800 & 1.820 & 0.307 \\
\hline rule of law & 1.360 & 1.430 & 0.390 & 1.940 & 0.455 \\
\hline control of corruption & 1.385 & 1.410 & 0.250 & 2.420 & 0.673 \\
\hline
\end{tabular}

Kaufmann et al. (2010) themselves acknowledge that the six variables should not be thought of as totally independent from one another. They are indeed positively correlated also for the countries selected here. The correlation matrix is provided in Table A1. Correlation is technically not a problem in non-parametric estimation, even though it has been argued that it artificially increases dimensionality. In our case, it is nevertheless even desirable to keep all the six variables. Explanation of results would otherwise lose implications since we want to determine in which areas of institutional quality, as defined by the Worldwide Government Indicators, the countries are behind, and how much they can improve relative to the institutionally most efficient countries. We will reduce dimensionality only in the robustness check and compare the resulting rankings.

The vector of inputs consists of only one element which is set equal to one for all observations. The purpose of the analysis was not to measure efficiency as such, but rather 
to find out where the countries can still improve in terms of institutional quality. We, nevertheless, acknowledge that there might be some "inputs" that are likely to "produce" our institutional quality variables. These might include, for instance, previous political experience or history of the particular country. These variables are nevertheless impossible to measure in such a way to be included into the analysis as inputs. Furthermore, since all these countries are in some kind of integration process, they all should be equal partners aiming at the same quality of institutions regardless of their historical experience - the same reasons why we consider only the constant returns to scale DEA model.

Institutional efficiency was estimated using Coelli‘s DEA Software DEAP Version 2.1. For PCA and general analyses the statistical software Gretl (Cottrell \& Lucchetti, 2007) was used.

\section{Empirical Results}

Results of the efficiency analysis are presented in column (3) in Table A2. Countries were ordered in a descending manner.

The interpretation of the efficiency score is such that when a country, e.g. the Czech Republic, reaches the efficiency score of 0.714 , it could increase its institutional efficiency by $40 \%$ relative to the most efficient observations. In other words, there is a scope for efficiency improvement reaching 28.6 percentage points. Higher scores imply a better ranking provided in column (4) of Table A2.

Average DEA-like efficiency of our sample is 0.811 meaning that on average there is an improvement potential of $23.3 \%$. Median efficiency value reaches 0.804 and standard deviation is 0.154 . These results are further supported by the distribution of DEA efficiency scores in Figure 1.

Figure 1

\section{Frequency Plot - DEA Efficiency}

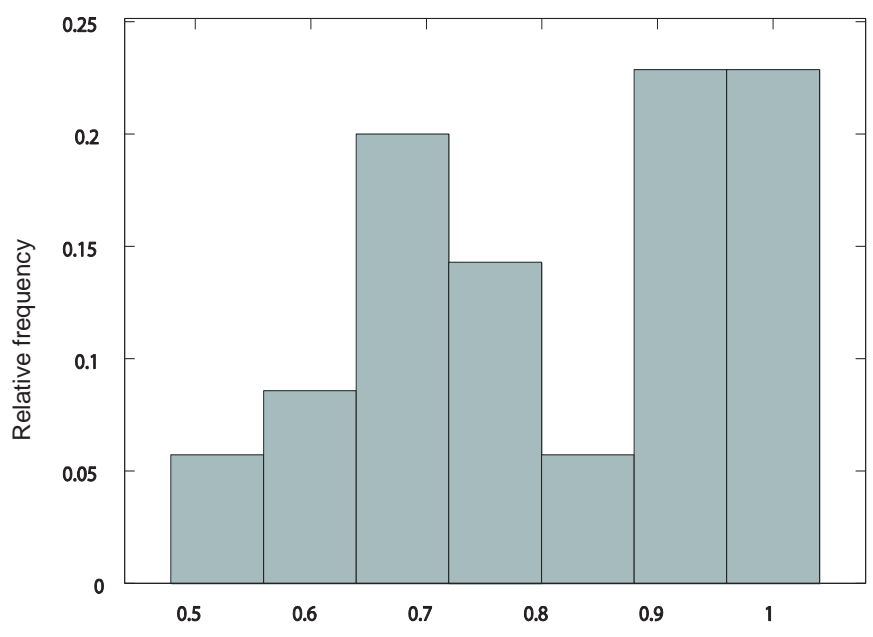


The most efficient countries includes the Nordic countries, i.e. Denmark, Finland, Norway, Sweden; and Luxembourg, New Zealand and Switzerland, which are immediately followed by the Netherlands. It suggests some clustering of institutionally efficient countries in northern Europe, which is to a large extent consistent with EspingAndersen's 1990 typology of social-democratic states. The front position of Switzerland may be explained by a considerable level of independence from the influence of various multinational institutions. The next most successful EU countries occupy then $12^{\text {th }}-16^{\text {th }}$ rank with scores above 0.88 . France takes the $18^{\text {th }}$ rank with score slightly above 0.80 and is thus the last country in the list to score above the average. EU countries of 2004 and 2007 accession, Portugal, Spain, Italy and Greece reach below average scores, with Estonia being most successful. The Czech Republic takes the $3^{\text {rd }}$ position among $10 \mathrm{New}$ EU Member States and is $24^{\text {th }}$ in the overall sample. The low efficiency scores of the Mediterranean countries is consistent with their recent poor economic development. It is also important to keep in mind that Spain, Italy and Greece, together with the United Kingdom, Cyprus and South Korea, did not reveal significant data for all 6 areas of interest which, by itself, signals some inconsistency in their policies.

In Table A3, we provide original values of the institutional quality variables together with their targets, i.e. what each country should be able to achieve relative to the rest of the sample. The target value was obtained as a linear combination of its peers (i.e. efficient observations that are placed on the frontier).

Table 2 through Table 7 show the countries which require the biggest and lowest improvements to be placed on the frontier, for each of the six variables considered. The outputoriented distance to the frontier is expressed both in absolute and relative terms. ${ }^{4}$ Neither fully efficient observations, nor observations that did not reveal reliable data for the particular indicator were considered.

Table 2

Highest and Lowest Necessary Improvements in (1) voice and accountability

\begin{tabular}{|l|c|c|l|c|c|}
\hline \multicolumn{3}{|c|}{ Highest } & \multicolumn{3}{c|}{ Lowest } \\
\hline country & $\%$ of original & abs.value & country & $\%$ of original & abs. value \\
\hline KOREA, SOUTH & 1.22 & 0.85 & NETHERLANDS & 0.01 & 0.01 \\
\hline LATVIA & 0.97 & 0.77 & ICELAND & 0.06 & 0.08 \\
\hline GREECE & 0.78 & 0.69 & CANADA & 0.07 & 0.11 \\
\hline LITHUANIA & 0.77 & 0.68 & AUSTRIA & 0.12 & 0.16 \\
\hline SLOVAKIA & 0.76 & 0.67 & AUSTRALIA & 0.12 & 0.17 \\
\hline
\end{tabular}

4 Column "\% of original" indicates, if multiplied by 100 , the percentage improvement with respect to the country's original value. Column "-." denotes absolute difference between the targeted and original value. 
Table 3

Highest and Lowest Necessary Improvements in (2) political stability

\begin{tabular}{|l|c|l|c|l|c|l|c|}
\hline \multicolumn{4}{|c|}{ Highest } & \multicolumn{4}{c|}{ Lowest } \\
\hline \multicolumn{2}{|c|}{$\%$ of original } & \multicolumn{1}{|c|}{ absolute difference } & \multicolumn{2}{c|}{$\%$ of original } & \multicolumn{2}{c|}{ absolute difference } \\
\hline country & value & country & value & country & value & country & value \\
\hline $\begin{array}{l}\text { UNITED } \\
\text { STATES }\end{array}$ & 2.32 & $\begin{array}{l}\text { UNITED } \\
\text { STATES }\end{array}$ & 0.95 & ICELAND & 0.06 & ICELAND & 0.07 \\
\hline LATVIA & 1.36 & ITALY & 0.66 & IRELAND & 0.10 & IRELAND & 0.10 \\
\hline ITALY & 1.25 & FRANCE & 0.61 & NETHERLANDS & 0.14 & NETHERLANDS & 0.13 \\
\hline FRANCE & 1.11 & LATVIA & 0.60 & CANADA & 0.18 & CANADA & 0.18 \\
\hline HUNGARY & 0.80 & LITHUANIA & 0.51 & AUSTRIA & 0.20 & AUSTRALIA & 0.21 \\
\hline
\end{tabular}

Table 4

Highest and Lowest Necessary Improvements in (3) government effectiveness

\begin{tabular}{|l|c|l|c|l|l|l|c|}
\hline \multicolumn{4}{|c|}{ Highest } & \multicolumn{4}{c|}{ Lowest } \\
\hline \multicolumn{2}{|c|}{$\%$ of original } & \multicolumn{2}{|c|}{ absolute difference } & \multicolumn{2}{c|}{$\%$ of original } & \multicolumn{2}{c|}{ absolute difference } \\
\hline country & value & country & value & country & value & country & value \\
\hline LATVIA & 2.42 & LATVIA & 1.55 & BELGIUM & 0.20 & BELGIUM & 0.30 \\
\hline ITALY & 2.33 & HUNGARY & 1.33 & CANADA & 0.20 & CANADA & 0.36 \\
\hline GREECE & 1.90 & LITHUANIA & 1.30 & NETHERLANDS & 0.22 & ICELAND & 0.36 \\
\hline HUNGARY & 1.83 & ITALY & 1.21 & ICELAND & 0.22 & NETHERLANDS & 0.37 \\
\hline LITHUANIA & 1.80 & $\begin{array}{l}\text { CZECH } \\
\text { REPUBLIC }\end{array}$ & 1.16 & AUSTRALIA & 0.26 & FRANCE & 0.39 \\
\hline
\end{tabular}

Table 5

Highest and Lowest Necessary Improvements in (4) regulatory quality

\begin{tabular}{|l|c|l|c|l|c|c|c|}
\hline \multicolumn{4}{|c|}{ Highest } & \multicolumn{4}{c|}{ Lowest } \\
\hline \multicolumn{2}{|c|}{$\%$ of original } & absolute difference & \multicolumn{2}{c|}{$\%$ of original } & \multicolumn{2}{c|}{ absolute difference } \\
\hline country & value & country & value & country & value & country & value \\
\hline $\begin{array}{l}\text { KOREA, } \\
\text { SOUTH }\end{array}$ & 1.05 & $\begin{array}{l}\text { KOREA. } \\
\text { SOUTH }\end{array}$ & 0.90 & NETHERLANDS & 0.01 & NETHERLANDS & 0.01 \\
\hline LATVIA & 0.86 & LATVIA & 0.84 & AUSTRALIA & 0.05 & AUSTRALIA & 0.08 \\
\hline SLOVENIA & 0.83 & ICELAND & 0.76 & CANADA & 0.07 & CANADA & 0.12 \\
\hline ICELAND & 0.79 & LITHUANIA & 0.75 & IRELAND & 0.10 & BELGIUM & 0.16 \\
\hline GREECE & 0.78 & SLOVENIA & 0.74 & GERMANY & 0.13 & IRELAND & 0.17 \\
\hline
\end{tabular}


Table 6

Highest and Lowest Necessary Improvements in (5) rule of law

\begin{tabular}{|l|c|l|c|l|c|l|c|}
\hline \multicolumn{5}{|c|}{ Highest } & \multicolumn{4}{c|}{ Lowest } \\
\hline \multicolumn{2}{|c|}{$\%$ of original } & absolute difference & \multicolumn{2}{c|}{$\%$ of original } & \multicolumn{2}{c|}{ absolute difference } \\
\hline country & value & country & value & country & value & country & value \\
\hline ITALY & 3.82 & ITALY & 1.49 & NETHERLANDS & 0.05 & NETHERLANDS & 0.09 \\
\hline SLOVAKIA & 1.94 & SLOVAKIA & 1.26 & CANADA & 0.07 & CANADA & 0.13 \\
\hline GREECE & 1.94 & GREECE & 1.24 & ICELAND & 0.08 & ICELAND & 0.14 \\
\hline POLAND & 1.71 & POLAND & 1.16 & AUSTRALIA & 0.08 & AUSTRALIA & 0.14 \\
\hline LITHUANIA & 1.58 & LITHUANIA & 1.14 & AUSTRIA & 0.10 & IRELAND & 0.18 \\
\hline
\end{tabular}

Table 7

Highest and Lowest Necessary Improvements in (6) control of corruption

\begin{tabular}{|l|r|l|r|l|l|l|r|}
\hline \multicolumn{4}{|c|}{ Highest } & \multicolumn{4}{c|}{ Lowest } \\
\hline \multicolumn{2}{|c|}{$\%$ of original } & \multicolumn{2}{l|}{ absolute difference } & \multicolumn{2}{c|}{$\%$ of original } & \multicolumn{2}{c|}{ absolute difference } \\
\hline country & value & country & value & country & value & country & value \\
\hline LITHUANIA & 7.95 & LATVIA & 2.12 & ICELAND & 0.06 & ICELAND & 0.11 \\
\hline LATVIA & 7.07 & LITHUANIA & 1.99 & NETHERLANDS & 0.09 & NETHERLANDS & 0.18 \\
\hline SLOVAKIA & 5.73 & SLOVAKIA & 1.84 & CANADA & 0.13 & CANADA & 0.26 \\
\hline HUNGARY & 3.97 & HUNGARY & 1.83 & AUSTRALIA & 0.19 & AUSTRALIA & 0.39 \\
\hline $\begin{array}{l}\text { CZECH } \\
\text { REPUBLIC }\end{array}$ & 3.92 & $\begin{array}{l}\text { CZECH } \\
\text { REPUBLIC }\end{array}$ & 1.81 & AUSTRIA & 0.27 & AUSTRIA & 0.47 \\
\hline
\end{tabular}

Countries that ended up in the worst performing group are to a large extent not a surprise for any of the indicators. Even the worst situation of the United States in indicator (2) political stability is not surprising keeping in mind the potential threat of terrorism, the USA. are facing. The countries which classified as needing the least improvement are considerably stable across indicators.

The Czech Republic ended up on the $24^{\text {th }}$ place from the total, however, among the new EU accession countries it ranks the $3^{\text {rd }}$, following Estonia and Malta. It reached overall efficiency score of 0.714 . As far as improvements in individual variables are concerned, it needs the $5^{\text {th }}$ biggest improvement in (6) control of corruption, both in absolute and relative terms. In (3) government effectiveness, the $5^{\text {th }}$ biggest improvement is also required, however, only in absolute terms. In summary, (1) voice and accountability needs to be increased by $45 \%$, (2) political stability by $40 \%$, (3) government effectiveness by $119 \%$, (4) regulatory quality by $40 \%$, (5) rule of law by $100 \%$ and (6) control of corruption by about $392 \%$ relative to its values of the Worldwide Governance Indicators published by the World Bank in 2009.

Targets of the Czech Republic were further compared to the results of Slovakia, which took the $30^{\text {th }}$ position reaching efficiency score of 0.645 . Panel (a) of Figure 2 depicts absolute differences between the original values and targets for the Czech 
Republic and Slovakia, panel (b) compares the necessary improvements for both countries in relative terms. Even though these two countries had a similar starting position in 1993, when they split, the results reveal that Slovakia needs to improve more in all the observed areas, both in absolute and relative terms. The only exception is (3) government effectiveness where Slovakia is slightly better, both in absolute and relative terms.

Figure 2

\section{Czech Republic vs. Slovakia}

(a) absolute terms

(1) Voice and accountability

(2) Political stability

(3) Government effectiveness

(4) Regulatory quality

(5) Rule of law

(6) Control of corruption

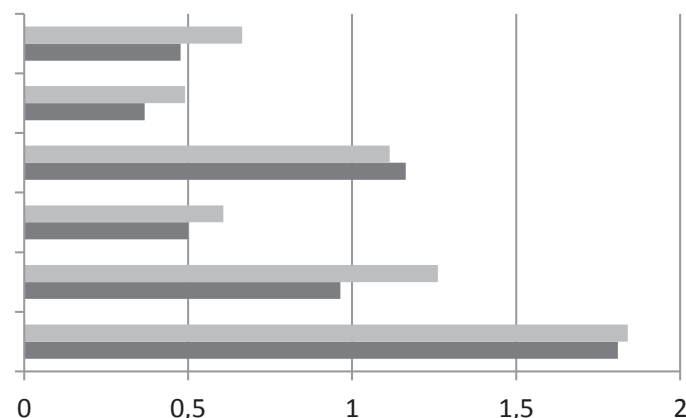

0

0,5

(b) relative terms

(1) Voice and accountability

(2) Political stability

(3) Government effectiveness

(4) Regulatory quality

(5) Rule of law

(6) Control of corruption

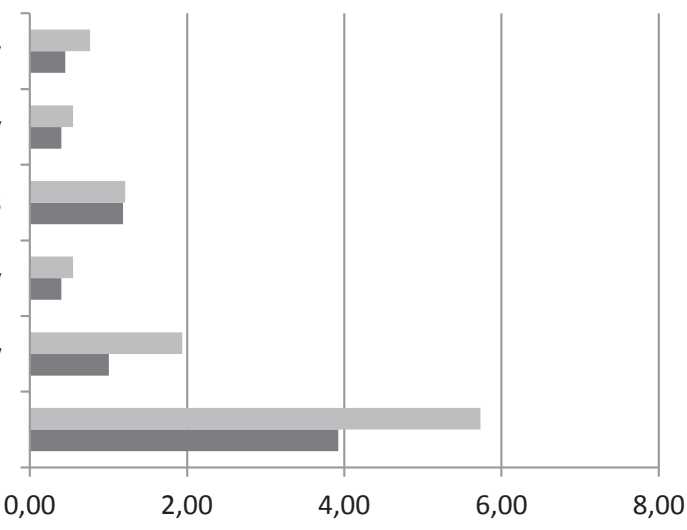

\subsection{Robustness check}

Our DEA-like approach provides us with invaluable information as to where each country should improve in terms of institutional quality, however, as also Kaufmann et al. (2010) pointed out and Table A1 revealed, the institutional quality variables are correlated. Even though correlation is technically not a problem in DEA, it is not ideal if the primary focus of the analysis are efficiency scores. We therefore tested 
correlation of efficiency results obtained from DEA and the Principal Component Analysis, which creates a system of coordinates uncorrelated to one another. Results of the PCA are provided in Table 8.

Table 8

\section{Principal Component Analysis}

\begin{tabular}{|l|c|c|c|c|c|c|}
\hline & PC1 & PC2 & PC3 & PC4 & PC5 & PC6 \\
\hline Eigenvalue & 4.9176 & 0.6275 & 0.2600 & 0.0915 & 0.0699 & 0.0335 \\
\hline Proportion & 0.8196 & 0.1046 & 0.0433 & 0.0152 & 0.0116 & 0.0056 \\
\hline Cummulative & 0.8196 & 0.9242 & 0.9675 & 0.9828 & 0.9944 & 1.0000 \\
\hline Component loadings \\
\hline Voice and accountability (1) & 0.431 & -0.100 & 0.210 & -0.837 & 0.244 & -0.009 \\
\hline Political stability (2) & 0.320 & -0.853 & -0.377 & 0.157 & -0.053 & 0.034 \\
\hline Government effectiveness (3) & 0.436 & 0.095 & 0.215 & 0.441 & 0.577 & -0.477 \\
\hline Regulatory quality (4) & 0.376 & 0.480 & -0.787 & -0.053 & 0.030 & 0.070 \\
\hline Rule of law (5) & 0.436 & 0.112 & 0.209 & 0.041 & -0.776 & -0.387 \\
\hline Control of corruption (6) & 0.437 & 0.106 & 0.323 & 0.276 & -0.030 & 0.785 \\
\hline
\end{tabular}

The first principal component explains over $81 \%$ of the data. We used only the first component to obtain a vector of institutional values. When looking at principal loadings for all the six variables for the first component, one notices that they are to some extent similar.

We multiplied the original variables by their loadings for the first component, the results of which are depicted in the $5^{\text {th }}$ column of Table A2. Descriptive statistics of the resulting values are provided in Table 9, together with the like for the DEA results. The graph of distribution of final PCA values is provided in Figure 3. Unfortunately the two sets of results are quantitatively not comparable since the latter is a transformation of the original data, while the former are efficiency scores spanning in the $[0 ; 1]$ interval.

Table 9

Descriptive Statistics of the Results

\begin{tabular}{|l|c|c|}
\hline & Efficiency DEA & PCA PC1 \\
\hline Mean & (1) & (2) \\
\hline Median & 0.811 & 3.217 \\
\hline Minimum & 0.804 & 3.197 \\
\hline Maximum & 1.000 & 1.622 \\
\hline St. Dev. & 0.154 & 0.517 \\
\hline
\end{tabular}




\section{Figure 3}

\section{Frequency PIot - PCA Values}

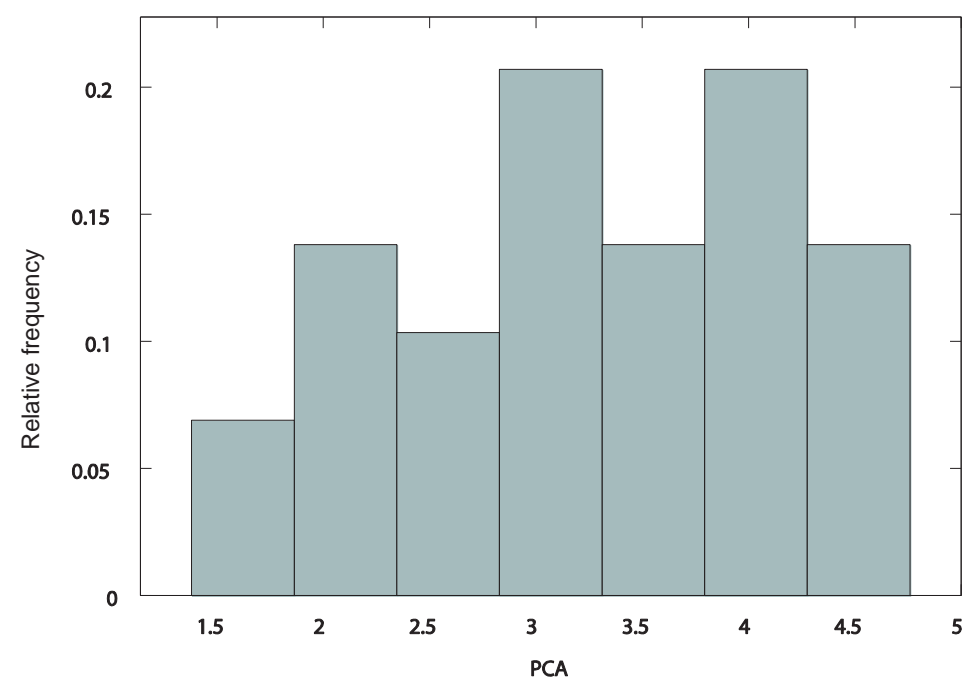

We therefore ranked the results of the PCA in the 6th column of Table A2, and calculated the Spearman's Rank Correlation Coefficient (Spearman, 1904) which proved to be 0.9653 . We significantly rejected the null hypothesis of no rank correlation even at $1 \%$ significance level. It has to be kept in mind in this context that the coefficient might still be slightly downward biased due to the fact that identical efficiency scores under DEA are ranked the same (for more discussion see Section 2) No two values were identical under PCA.

\section{Conclusions}

This paper builds on a widespread application of institutional variables in growth and other macroeconomic regressions. The general results show that better institutions determine higher income and investments, institutional improvements lead to higher rates of economic growth (even though in a considerable time lag). Building of institutions can thus be thought of as a form of technology transfer that allows increased productivity.

We looked at institutions from a different perspective. Using Worldwide Governance Indicators published by the World Bank in 2009, we employed an output-oriented Data Envelopment Analysis (DEA-like) approach, where the six institutional quality indicators constituted a vector of outputs. Inputs were set equal to 1 for all countries. We were interested in institutional quality of a statistically homogeneous sample of 35 countries (EU and OECD members) and assumed that all countries should aim at identical institutional quality regardless of their "inputs", the more so that these countries are in an advanced process of regional or economic integration. 
We analyzed the position of individual countries in the sample with respect to the six Worldwide Governance Indicators. It allowed us to determine in which areas of institutional quality each country is lacking and by how much, relative to the best performers in the sample. We also aggregated the indicators and constructed relative efficiency scores lying in the interval [0;1].

Average efficiency of the sample reached 0.811 , median was 0.804 . The most institutionally efficient countries are situated in northern Europe. As far as major and minor necessary improvements are concerned, the results were not surprising. The Czech Republic took up the $24^{\text {th }}$ rank in the overall sample and the $3^{\text {rd }}$ among New EU Member States. Major improvements here were found to be necessary in the area of government effectiveness and control of corruption where it scored among the 5 worst countries. However, in comparison with Slovakia, the Czech Republic scored better in most areas.

We then carried out a robustness check of the aggregated results using the Principal Component Analysis and computed Spearman's Rank Correlation Coefficient. DEA and PCA scores were significantly correlated with the coefficient of 0.9653 . The significant qualitative correlation between the two sets of results suggests, that our efficiency scores could equally well be employed in growth and other regressions requiring institutional quality as an explanatory variable - however, as literature suggests, some lag with respect to other variables of the growth regression should be considered.

The advantage of the DEA-like non-parametric method stems from the fact it can be adjusted for any variables, including those that are expressed in natural units only (such as days required to obtain a construction permit). The motivation for further research thus is to use a different sets of institutional quality variables and compare the resulting scores and rankings with those obtained in this paper.

\section{References}

Adkins, L. C., Moomaw, R. L., Savvides, A. (2002), "Institutions, Freedom, and Technical Efficiency." Southern Economic Journal 69(1): pp. 92-108.

Aron, J. (2000), "Growth and Institutions: A Review of the Evidence." World Bank Research Observer 15(1): pp. 99-135.

Barro, R. J. (1991), "Economic Growth in a Cross Section of Countries." The Quarterly Journal of Economics 106(2): pp. 407-43.

Borrmann, A., Busse, M., Neuhaus, S. (2006), "Institutional Quality and the Gains from Trade." Kyklos 59(3): pp. 345-368.

Bourguignon, F., Verdier, T. (2000), "Oligarchy, Democracy, Inequality and Growth." Journal of Development Economics 62(2): pp. 285-313.

Charnes, A., Cooper, W. W., Rhodes, E. (1978), "Measuring Efficiency of Decision Making Units." European Journal of Operational Research 2: pp. 429-444.

Chong, A., Calderon, C. (2000a), "Causality and Feedback between Institutional Measures and Economic Growth." Economics and Politics 12(1): pp. 69-81. 
Chong, A., Calderon, C. (2000b), "Institutional Quality and Poverty Measures in a Cross-section of Countries." Economics of Governance 1(2): pp. 123-135.

Chong, A., Calderon, C. (2000), "Institutional Quality and Income Distribution." Economic Development and Cultural Change 48(4): pp. 761-86.

Chousa, J. P., Khan, H. A., Melikyan, D., Tamazian, A. (2004), "Assessing Institutional Efficiency, Growth and Integration." (CIRJE-F-285).

Coelli, T. J. (1996), A Guide to DEAP Version 2.1: A Data Envelopment Analysis (Computer Program, Working Paper 08/96. Centre for Efficiency and Productivity Analysis (CEPA), CEPA Working Papers Department of Econometrics University of New England Armidale, NSW 2351s, Australia.

Cottrell, A., Lucchetti, R. (2007), Gretl User's Guide. Available at http://ricardo.ecn.wfu.edu/pub// gretl/manual/ en/gretl-guide.pdf.

Esping-Andersen, G. (1990), The Three Worlds of Welfare Capitalism. Cambridge: Polity Press.

Farrell, M. J. (1957), "The Measurement of Productive Efficiency." Journal of the Royal Statistical Society. Series A (General) 120:3: pp. 253-290.

Gastil, R. D. (1983, 1986): Freedom in the World. Greenwood, Westport, Conn.

Gwartney, J., Lawson, R., Block, W. (2003), "Economic Freedom of the World: 2003 Annual Report." Technical Report, Frazier Institute, Vancouver.

Gwartney, J. D., Holcome, R. G., Lawson, A. (2004), "Economic Freedom, Institutional Quality, and Cross-country Differences in Income and Growth." Cato Journal 24: pp. 205-233.

Jolliffe, I. T. (2002), Principal Component Analysis. Springer USA.

Kaufmann, D., Kraay, A., Mastruzzi, M. (2010), "The Worldwide Governance Indicators: Methodology and Analytical Issues." Technical report, The World Bank.

Knack, S., Keefer, P. (1995), "Institutions and Economic Performance: Cross-country Tests Using Alternative Institutional Indicators." (23118).

Kormendi, R. C., Meguire, P. G. (1985), "Macroeconomic Determinants of Growth: Cross-country Evidence." Journal of Monetary Economics 16(2): pp. 141-163.

Levchenko, A. A. (2007): "Institutional Quality and International Trade." Review of Economic Studies 74(3): pp. 791-819.

Mauro, P. (1995), "Corruption and growth." The Quarterly Journal of Economics 110(3): pp. 681-712.

Rodrik, D. (2000), "Institutions for High-quality Growth: What They Are and How to Acquire them." (7540).

Romer, P. M. (1994), "New Goods, Old Theory, and the Welfare Costs of Trade Restrictions." (4452).

Scully, G. W. (1988), "The Institutional Framework and Economic Development." Journal of Political Economy 96(3): pp. 652-62.

Shephard, R. W. (1970), Theory of Cost and Production Functions, by Ronald W. Shephard. Princeton University Press, Princeton, N.J.

Spearman, C. (1904), "The Proof and Measurement of Association between Two Things." American Journal of Psychology 15: pp. 72\{101.

WEF (1980-2010), The Global Competitiveness Report. Journal, IMD International (Institute) and World Economic Forum.

Wheeler, D., Mody, A. (1992), "International Investment Location Decisions: The Case of U.S. Firms." Journal of International Economics 33(1-2): pp. 57-76.

World Bank (2004-2011), Doing Business 2004-2011. Technical Report, World Bank. 


\section{Appendix}

Table A1

\section{Correlation Matrix}

\begin{tabular}{|c|c|c|c|c|c|c|}
\hline $\begin{array}{c}\text { voice and } \\
\text { accountability }\end{array}$ & $\begin{array}{l}\text { political } \\
\text { stability }\end{array}$ & $\begin{array}{c}\text { government } \\
\text { effectiveness }\end{array}$ & $\begin{array}{c}\text { regulatory } \\
\text { quality }\end{array}$ & rule of law & $\begin{array}{l}\text { control of } \\
\text { corruption }\end{array}$ & \\
\hline (1) & (2) & (3) & (4) & (5) & (6) & \\
\hline \multirow[t]{6}{*}{1} & 0.7087 & 0.8596 & 0.7723 & 0.8741 & 0.9105 & (1) \\
\hline & 1 & 0.6507 & 0.4547 & 0.6438 & 0.6048 & (2) \\
\hline & & 1 & 0.8144 & 0.9357 & 0.9474 & (3) \\
\hline & & & 1 & 0.8288 & 0.7873 & (4) \\
\hline & & & & 1 & 0.9513 & (5) \\
\hline & & & & & 1 & (6) \\
\hline
\end{tabular}

Table A2

\section{Efficiency Results}

\begin{tabular}{|c|c|c|c|c|c|}
\hline Country & ID & Efficiency & Rank_DEA & PCA_PC1 & Rank_PCA \\
\hline (1) & (2) & (3) & (4) & (5) & (6) \\
\hline DENMARK & 6 & 1.000 & 1 & 4.517 & 1 \\
\hline FINLAND & 8 & 1.000 & 1 & 4.490 & 2 \\
\hline LUXEMBOURG & 19 & 1.000 & 1 & 4.172 & 5 \\
\hline NEW ZEALAND & 21 & 1.000 & 1 & 4.317 & 4 \\
\hline NORWAY & 22 & 1.000 & 1 & 4.002 & 9 \\
\hline SWEDEN & 28 & 1.000 & 1 & 4.332 & 3 \\
\hline SWITZERLAND & 29 & 1.000 & 1 & 4.121 & 6 \\
\hline NETHERLANDS & 20 & 0.992 & 8 & 4.034 & 7 \\
\hline AUSTRALIA & 1 & 0.956 & 9 & 3.919 & 10 \\
\hline ICELAND & 14 & 0.948 & 10 & 3.734 & 12 \\
\hline CANADA & 4 & 0.932 & 11 & 4.007 & 8 \\
\hline AUSTRIA & 2 & 0.907 & 12 & 3.748 & 11 \\
\hline IRELAND & 15 & 0.906 & 13 & 3.581 & 13 \\
\hline GERMANY & 10 & 0.889 & 14 & 3.523 & 14 \\
\hline BELGIUM & 3 & 0.886 & 15 & 3.197 & 15 \\
\hline UNITED KINGDOM & 30 & 0.885 & 16 & . & . \\
\hline CHILE & 13 & 0.824 & 17 & 2.851 & 20 \\
\hline FRANCE & 9 & 0.804 & 18 & 3.034 & 16 \\
\hline ESTONIA & 7 & 0.791 & 19 & 2.653 & 21 \\
\hline UNITED STATES & 31 & 0.789 & 20 & 2.910 & 17 \\
\hline MALTA & 35 & 0.788 & 21 & 2.904 & 18 \\
\hline PORTUGAL & 24 & 0.771 & 22 & 2.618 & 22 \\
\hline SPAIN & 27 & 0.760 & 23 & . & . \\
\hline CZECH REPUBLIC & 5 & 0.714 & 24 & 2.268 & 24 \\
\hline CYPRUS & 32 & 0.709 & 25 & . & . \\
\hline JAPAN & 17 & 0.687 & 26 & 2.861 & 19 \\
\hline ITALY & 16 & 0.662 & 27 & . & . \\
\hline POLAND & 23 & 0.662 & 27 & 1.870 & 27 \\
\hline HUNGARY & 12 & 0.646 & 29 & 1.918 & 25 \\
\hline SLOVAKIA & 25 & 0.645 & 30 & 1.898 & 26 \\
\hline SLOVENIA & 26 & 0.638 & 31 & 2.493 & 23 \\
\hline LITHUANIA & 34 & 0.565 & 32 & 1.692 & 28 \\
\hline GREECE & 11 & 0.561 & 33 & . & . \\
\hline LATVIA & 33 & 0.538 & 34 & 1.622 & 29 \\
\hline KOREA, SOUTH & 18 & 0.519 & 35 & & \\
\hline
\end{tabular}


Table A3

Countries - Original vs. Projected Values and Absolute and Relative Differences

\begin{tabular}{|c|c|c|c|c|c|c|c|c|c|c|c|c|c|c|c|c|c|c|c|c|c|c|c|c|}
\hline Country & (1) voi & ice and & accoun & ability & & politica & I stabi & & (3) gov & ernmen & effect & jeness & (4) & regulat & ory que & & & (5) rule & of law & & (6) $\mathrm{c}$ & ontrol o & f corru & tion \\
\hline & original & target & $\%$ & - & original & target & $\%$ & - & original & target & $\%$ & - & original & target & $\%$ & - & original & target & $\%$ & - & original & target & $\%$ & - \\
\hline (1) & (2) & (3) & (4) & (5) & (6) & (7) & (8) & (9) & (10) & (11) & (12) & (13) & (14) & (15) & (16) & (17) & (18) & (19) & (20) & (21) & (22) & (23) & (24) & (25) \\
\hline AUSTRALIA & 1.39 & 1.56 & 0.12 & 0.17 & 0.83 & 1.04 & 0.25 & 0.21 & 1.74 & 2.19 & 0.26 & 0.45 & 1.74 & 1.82 & 0.05 & 0.08 & 1.73 & 1.87 & 0.08 & 0.14 & 2.03 & 2.42 & 0.19 & 0.39 \\
\hline AUSTRIA & 1.37 & 1.53 & 0.12 & 0.16 & 1.13 & 1.36 & 0.20 & 0.23 & 1.63 & 2.13 & 0.31 & 0.50 & 1.47 & 1.73 & 0.18 & 0.26 & 1.76 & 1.94 & 0.10 & 0.18 & 1.75 & 2.22 & 0.27 & 0.47 \\
\hline BELGIUM & 1.39 & 1.57 & 0.13 & 0.18 & 0.79 & 1.18 & 0.49 & 0.39 & 1.48 & 1.78 & 0.20 & 0.30 & 1.27 & 1.43 & 0.13 & 0.16 & 1.37 & 1.88 & 0.37 & 0.51 & 1.43 & 1.99 & 0.39 & 0.56 \\
\hline CANADA & 1.44 & 1.55 & 0.07 & 0.11 & 1.02 & 1.20 & 0.18 & 0.18 & 1.78 & 2.14 & 0.20 & 0.36 & 1.64 & 1.76 & 0.07 & 0.12 & 1.78 & 1.91 & 0.07 & 0.13 & 2.04 & 2.30 & 0.13 & 0.26 \\
\hline CZECH REPUBLIC & 1.06 & 1.54 & 0.45 & 0.48 & 0.92 & 1.29 & 0.40 & 0.37 & 0.98 & 2.14 & 1.19 & 1.16 & 1.25 & 1.75 & 0.40 & 0.50 & 0.96 & 1.92 & 1.00 & 0.96 & 0.46 & 2.27 & 3.92 & 1.81 \\
\hline DENMARK & 1.56 & 1.56 & 0.00 & 0.00 & 1.04 & 1.04 & 0.00 & 0.00 & 2.19 & 2.19 & 0.00 & 0.00 & 1.82 & 1.82 & 0.00 & 0.00 & 1.87 & 1.87 & 0.00 & 0.00 & 2.42 & 2.42 & 0.00 & 0.00 \\
\hline ESTONIA & 1.11 & 1.56 & 0.41 & 0.45 & 0.59 & 1.04 & 0.76 & 0.45 & 1.18 & 2.19 & 0.86 & 1.01 & 1.44 & 1.82 & 0.26 & 0.38 & 1.13 & 1.87 & 0.65 & 0.74 & 1.00 & 2.42 & 1.42 & 1.42 \\
\hline FINLAND & 1.53 & 1.53 & 0.00 & 0.00 & 1.36 & 1.36 & 0.00 & 0.00 & 2.13 & 2.13 & 0.00 & 0.00 & 1.73 & 1.73 & 0.00 & 0.00 & 1.94 & 1.94 & 0.00 & 0.00 & 2.22 & 2.22 & 0.00 & 0.00 \\
\hline FRANCE & 1.26 & 1.57 & 0.24 & 0.31 & 0.55 & 1.16 & 1.11 & 0.61 & 1.44 & 1.83 & 0.27 & 0.39 & 1.19 & 1.48 & 0.24 & 0.29 & 1.43 & 1.88 & 0.31 & 0.45 & 1.41 & 2.04 & 0.45 & 0.63 \\
\hline GERMANY & 1.39 & 1.56 & 0.13 & 0.17 & 0.85 & 1.10 & 0.29 & 0.25 & 1.48 & 2.01 & 0.36 & 0.53 & 1.47 & 1.65 & 0.13 & 0.18 & 1.63 & 1.87 & 0.15 & 0.24 & 1.70 & 2.24 & 0.31 & 0.54 \\
\hline GREECE & 0.88 & 1.57 & 0.78 & 0.69 & & 0.00 & . & & 0.61 & \begin{tabular}{|l|}
1.77 \\
\end{tabular} & 1.90 & 1.16 & 0.80 & 1.43 & 0.78 & 0.63 & 0.64 & 1.88 & 1.94 & 1.24 & & 0.00 & & \\
\hline HUNGARY & 1.01 & 1.56 & 0.55 & 0.55 & 0.60 & 1.08 & 0.80 & 0.48 & 0.73 & 2.06 & 1.83 & 1.33 & 1.10 & 1.70 & 0.55 & 0.60 & 0.82 & 1.87 & 1.28 & 1.05 & 0.46 & 2.29 & 3.97 & 1.83 \\
\hline CHILE & 0.96 & 1.56 & 0.63 & 0.60 & 0.63 & 1.04 & 0.65 & 0.41 & 1.21 & 2.19 & 0.81 & 0.98 & 1.50 & 1.82 & 0.21 & 0.32 & 1.25 & 1.87 & 0.50 & 0.62 & 1.37 & 2.42 & 0.77 & 1.05 \\
\hline ICELAND & 1.47 & 1.55 & 0.06 & 0.08 & 1.21 & 1.28 & 0.06 & 0.07 & 1.61 & 1.97 & 0.22 & 0.36 & 0.96 & 1.72 & 0.79 & 0.76 & 1.72 & 1.86 & 0.08 & 0.14 & 2.06 & 2.17 & 0.06 & 0.11 \\
\hline IRELAND & 1.37 & 1.55 & 0.13 & 0.18 & 0.98 & 1.08 & 0.10 & 0.10 & 1.30 & 2.13 & 0.64 & 0.83 & 1.63 & 1.80 & 0.10 & 0.17 & 1.71 & 1.89 & 0.10 & 0.18 & 1.72 & 2.38 & 0.39 & 0.66 \\
\hline ITALY & 1.04 & 1.57 & 0.51 & 0.53 & 0.53 & 1.19 & 1.25 & 0.66 & 0.52 & 1.73 & 2.33 & 1.21 & 0.90 & 1.39 & 0.54 & 0.49 & 0.39 & 1.88 & 3.82 & 1.49 & & 0.00 & & \\
\hline JAPAN & 1.03 & 1.54 & 0.49 & 0.51 & 0.95 & 1.38 & 0.46 & 0.43 & 1.26 & 2.02 & 0.60 & 0.76 & 1.07 & 1.70 & 0.59 & 0.63 & 1.31 & 1.91 & 0.46 & 0.60 & 1.35 & 2.15 & 0.59 & 0.80 \\
\hline KOREA, SOUTH & 0.69 & 1.54 & 1.22 & 0.85 & & 0.00 & 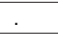 & & 1.11 & 2.14 & 0.93 & 1.03 & 0.85 & 1.75 & 1.05 & 0.90 & 1.00 & 1.93 & 0.93 & 0.93 & 0.52 & 2.25 & 3.33 & 1.73 \\
\hline LUXEMBOURG & 1.55 & 1.55 & 0.00 & 0.00 & 1.44 & 1.44 & 0.00 & 0.00 & 1.76 & 1.76 & 0.00 & 0.00 & 1.64 & 1.64 & 0.00 & 0.00 & 1.83 & 1.83 & 0.00 & 0.00 & 1.97 & 1.97 & 0.00 & 0.00 \\
\hline NETHERLANDS & 1.55 & 1.56 & 0.01 & 0.01 & 0.95 & 1.08 & 0.14 & 0.13 & 1.69 & 2.06 & 0.22 & 0.37 & 1.68 & 1.69 & 0.01 & 0.01 & 1.78 & 1.87 & 0.05 & 0.09 & 2.10 & 2.28 & 0.09 & 0.18 \\
\hline NEW ZEALAND & 1.49 & 1.49 & 0.00 & 0.00 & 0.99 & 0.99 & 0.00 & 0.00 & 1.88 & 1.88 & 0.00 & 0.00 & 1.77 & 1.77 & 0.00 & 0.00 & 1.91 & 1.91 & 0.00 & 0.00 & 2.38 & 2.38 & 0.00 & 0.00 \\
\hline NORWAY & 1.57 & 1.57 & 0.00 & 0.00 & 1.19 & 1.19 & 0.00 & 0.00 & 1.73 & \begin{tabular}{|l|}
1.73 \\
\end{tabular} & 0.00 & 0.00 & 1.39 & 1.39 & 0.00 & 0.00 & 1.88 & 1.88 & 0.00 & 0.00 & 1.94 & 1.94 & 0.00 & 0.00 \\
\hline POLAND & 1.03 & 1.56 & 0.51 & 0.53 & 0.91 & 1.37 & 0.51 & 0.46 & 0.64 & 1.75 & 1.74 & 1.11 & 0.93 & 1.57 & 0.69 & 0.64 & 0.68 & 1.84 & 1.71 & 1.16 & 0.48 & 1.96 & 3.09 & 1.48 \\
\hline PORTUGAL & 1.21 & 1.57 & 0.30 & 0.36 & 0.79 & 1.19 & 0.51 & 0.40 & 1.21 & 1.73 & 0.43 & 0.52 & 1.04 & 1.39 & 0.34 & 0.35 & 1.04 & 1.88 & 0.81 & 0.84 & 1.08 & 1.94 & 0.80 & 0.86 \\
\hline SLOVAKIA & 0.87 & 1.54 & 0.76 & 0.67 & 0.89 & 1.38 & 0.55 & 0.49 & 0.92 & 2.03 & 1.21 & 1.11 & 1.10 & 1.71 & 0.55 & 0.61 & 0.65 & 1.91 & 1.94 & 1.26 & 0.32 & 2.16 & 5.73 & 1.84 \\
\hline SLOVENIA & 0.99 & 1.55 & 0.57 & 0.56 & 0.87 & 1.37 & 0.57 & 0.50 & 1.16 & 1.82 & 0.57 & 0.66 & 0.89 & 1.63 & 0.83 & 0.74 & 1.11 & 1.81 & 0.63 & 0.70 & 1.06 & 2.00 & 0.89 & 0.94 \\
\hline SPAIN & 1.19 & 1.57 & 0.32 & 0.38 & . & 0.00 & . & & 0.94 & \begin{tabular}{|l|}
1.89 \\
\end{tabular} & $\begin{array}{l}1.01 \\
\end{array}$ & 0.95 & 1.17 & 1.54 & 0.32 & 0.37 & 1.13 & 1.88 & 0.66 & 0.75 & 1.01 & 2.11 & 1.09 & 1.10 \\
\hline SWEDEN & 1.56 & 1.56 & 0.00 & 0.00 & 1.10 & 1.10 & 0.00 & 0.00 & 1.99 & \begin{tabular}{|l|}
1.99 \\
\end{tabular} & 0.00 & 0.00 & 1.66 & 1.66 & 0.00 & 0.00 & 1.93 & 1.93 & 0.00 & 0.00 & 2.23 & 2.23 & 0.00 & 0.00 \\
\hline SWITZERLAND & 1.56 & 1.56 & 0.00 & 0.00 & 1.21 & 1.21 & 0.00 & 0.00 & 1.92 & 1.92 & 0.00 & 0.00 & 1.55 & 1.55 & 0.00 & 0.00 & 1.75 & 1.75 & 0.00 & 0.00 & 2.01 & 2.01 & 0.00 & 0.00 \\
\hline UNITED KINGDOM & 1.31 & 1.52 & 0.16 & 0.21 & ${ }^{\circ}$ & 0.00 & . & & 1.48 & 2.07 & 0.40 & 0.59 & 1.54 & 1.74 & 0.13 & 0.20 & 1.71 & 1.93 & 0.13 & 0.22 & 1.54 & 2.26 & 0.47 & 0.72 \\
\hline UNITED STATES & 1.11 & 1.53 & 0.38 & 0.42 & 0.41 & 1.36 & 2.32 & 0.95 & 1.39 & 2.13 & 0.53 & 0.74 & 1.36 & 1.73 & 0.27 & 0.37 & 1.53 & 1.94 & 0.27 & 0.41 & 1.18 & 2.22 & 0.88 & 1.04 \\
\hline CYPRUS & 1.06 & 1.56 & 0.47 & 0.50 & & 0.00 & & & 1.32 & 2.19 & 0.66 & 0.87 & 1.29 & 1.82 & 0.41 & 0.53 & 1.16 & 1.87 & 0.61 & 0.71 & 1.00 & 2.42 & 1.42 & 1.42 \\
\hline LATVIA & 0.79 & 1.56 & 0.97 & 0.77 & 0.44 & 1.04 & 1.36 & 0.60 & 0.64 & 2.19 & 2.42 & 1.55 & 0.98 & 1.82 & 0.86 & 0.84 & 0.83 & 1.87 & 1.25 & 1.04 & 0.30 & 2.42 & 7.07 & 2.12 \\
\hline LITHUANIA & 0.88 & 1.56 & 0.77 & 0.68 & 0.66 & 1.17 & 0.77 & 0.51 & 0.72 & 2.02 & 1.80 & 1.30 & 0.97 & 1.72 & 0.77 & 0.75 & 0.72 & 1.86 & 1.58 & 1.14 & 0.25 & 2.24 & 7.95 & 1.99 \\
\hline MALTA & 1.21 & 1.54 & 0.27 & 0.33 & 1.06 & 1.35 & 0.27 & 0.29 & 1.11 & 2.06 & 0.86 & 0.95 & 1.35 & 1.71 & 0.27 & 0.36 & 1.51 & 1.92 & 0.27 & 0.41 & 0.90 & 2.19 & 1.43 & 1.29 \\
\hline
\end{tabular}

